\title{
Cyclic Shear Behavior of High-Strength Concrete Structural Walls
}

\author{
by Susanto Teng and Jimmy Chandra
}

\begin{abstract}
High-strength concrete (HSC) walls having compressive strength of approximately $100 \mathrm{MPa}(14,500 \mathrm{psi})$ were tested under cyclic lateral loading to investigate their shear behavior. The parameters included were height-to-length ratio of the walls, vertical and horizontal web reinforcement ratios, and the effects of boundary elements in the form of flanges. The experimental results show that shorter walls exhibit greater shear strength than taller walls. Both vertical and horizontal web reinforcements contribute significantly to increasing the shear strength of the walls, with the horizontal web reinforcement being more effective for walls having height-tolength ratio from 1.0 to 2.0. With increase in height-to-length ratio of walls, the concrete contribution to the shear strength decreases while the web reinforcement contribution increases. The presence of flanges also significantly increases the shear strength of HSC walls. Experimental wall shear strengths from this study as well as from literature were compared with predictions from the ACI Code and Eurocode provisions. It can be seen that both ACI and Eurocode do not give consistent safety factors. The ACI method can be unsafe for low-strength concrete walls, while the Eurocode is overly conservative in almost all cases.
\end{abstract}

Keywords: boundary element; building codes; height-to-length ratio; highstrength concrete (HSC) walls; shear behavior; shear strength; web reinforcement ratio.

\section{INTRODUCTION}

Reinforced concrete (RC) walls are one of the most critical structural members in buildings to carry lateral loadings from wind, earthquake, as well as gravity. In typical buildings, it can be in the form of shear walls or core walls for lifts or staircases. Despite their importance, the behavior of structural walls is not yet fully understood. ACI $318^{1}$ and Eurocode $8^{2}$ provide guidance for designing structural walls, but their safety factors are still not uniform across relevant ranges of many important design parameters.

Previous studies by Cardenas and Magura $^{3}$ and Cardenas et al. ${ }^{4}$ show that the nominal strength of highrise $\mathrm{RC}$ walls with height-to-length ratio $\left(h_{w} / l_{w}\right)$ greater than 2.0 is governed more by flexural action, while the nominal strength of low-rise RC walls with $h_{w} / l_{w}$ less than 2.0 is governed more by shear action. It is generally understood that flexural strength can be predicted reasonably accurately using flexural theory while shear strength determination is more complex.

There are very few experiments that investigate shear behavior of high-strength concrete (HSC) walls with compressive strength $\left(f_{c}{ }^{\prime}\right)$ of $100 \mathrm{MPa}(14,500 \mathrm{psi})$ and higher. As the use of HSC as structural material becomes more common in engineering practice nowadays, it is neces- sary to study the behavior of such HSC walls and factors affecting it.

This current investigation concentrates on walls failing in shear. The parameters investigated include $h_{w} / l_{w}$ of walls, vertical and horizontal web reinforcement ratios $\left(\rho_{v}\right.$ and $\left.\rho_{h}\right)$, and the effect of wall flanges. The specimens were subjected to vertical axial loading and in-plane cyclic lateral loading which is assumed to simulate typical lateral loading due to earthquake.

\section{RESEARCH SIGNIFICANCE}

This study focuses on experimental investigation of the cyclic shear behavior of high strength concrete (HSC) walls with $f_{c}^{\prime}$ of approximately $100 \mathrm{MPa}(14,500 \mathrm{psi})$. The authors expect that, in addition to providing additional data on HSC walls, this study can also provide useful information for the better understanding of shear behavior of HSC walls subjected to cyclic lateral loading.

\section{BUILDING CODE PROVISIONS $\mathrm{ACl} 318$ provisions}

According to ACI 318, Chapter $18,{ }^{1}$ the nominal shear strength of RC walls can be calculated as follows (in SI units)

$$
V_{n}=A_{c v}\left(\alpha_{c} \lambda \sqrt{f_{c}^{\prime}}+\rho_{t} f_{y}\right)
$$

where $V_{n}$ is nominal shear strength, in $\mathrm{N} ; A_{c v}$ is gross area of concrete section bounded by web thickness and length of section in the direction of shear force considered, in $\mathrm{mm}^{2} ; \alpha_{c}$ is coefficient defining the relative contribution of concrete strength to nominal wall shear strength, which may be taken as 0.25 for $h_{w} / l_{w} \leq 1.5,0.17$ for $h_{w} / l_{w} \geq 2.0$, and varies linearly between 0.25 and 0.17 for $h_{w} / l_{w}$ between 1.5 and 2.0 (these coefficient values are valid for SI units); $\lambda$ is modification factor reflecting the reduced mechanical properties of lightweight concrete, all relative to normalweight concrete of the same compressive strength; $f_{c}{ }^{\prime}$ is specified compressive strength of concrete, in MPa; $\rho_{t}$ is ratio of area of distributed transverse (horizontal) reinforcement to gross concrete area perpendicular to that reinforcement; and $f_{y}$ is specified yield strength of reinforcement, in $\mathrm{MPa}$.

ACI Structural Journal, V. 113, No. 6, November-December 2016

MS No. S-2015-410.R1, doi: 10.14359/51689158, was received December 4, 2015, and reviewed under Institute publication policies. Copyright $(C) 2016$, American Concrete Institute. All rights reserved, including the making of copies unless permission is obtained from the copyright proprietors. Pertinent discussion including author's closure, if any, will be published ten months from this journal's date if the discussion is received within four months of the paper's print publication. 
Furthermore, ACI $318^{1}$ also limits that the value of $V_{n}$ shall not be taken larger than $0.83 A_{c w} \sqrt{ } f_{c}{ }^{\prime}$, where $A_{c w}$ is the area of concrete section of the individual vertical wall segment considered.

\section{Eurocode 8 provisions}

In this study, Eurocode $8^{2}$ provisions for ductile RC walls were used to calculate the shear strength of specimens collected. According to the Eurocode 8, the ultimate shear strength (resistance) of RC walls is taken as the minimum shear strength between two failure modes - that is, diagonal compression failure of the web due to shear, $V_{R d \text {,max }}$, and diagonal tension failure of the web due to shear (either $V_{R d, s}$ or $V_{R d}$ as explained later). The formulations are described as follows:

- Diagonal compression failure of the web due to shear

$$
V_{R d, \text { max }}=\alpha_{c w} b_{w} z v_{1} f_{c d} /(\cot \theta+\tan \theta)
$$

where $V_{R d, \max }$ is design value of the maximum shear force which can be sustained by the member, limited by crushing of the compression struts. For the critical region, the value is taken as $40 \%$ of the value outside the critical region; $\alpha_{c w}$ is a coefficient taking account of the state of the stress in the compression chord. The recommended value of $\alpha_{c w}$ is as follows

\section{0 for non-prestressed structures}

$$
\begin{gathered}
\left(1.0+\sigma_{c p} / f_{c d}\right) \text { for } 0<\sigma_{c p} \leq 0.25 f_{c d} \\
1.25 \text { for } 0.25 f_{c d}<\sigma_{c p} \leq 0.5 f_{c d} \\
2.5\left(1.0-\sigma_{c p} / f_{c d}\right) \text { for } 0.5 f_{c d}<\sigma_{c p}<1.0 f_{c d}
\end{gathered}
$$

$\sigma_{c p}$ is mean compressive stress, measured positive, in the concrete due to the design axial force; $b_{w}$ is minimum width of wall web between tension and compression chords; $z$ is inner lever arm, which is taken as $0.8 l_{w}$ ( $l_{w}$ is wall length); $v_{1}$ is a strength reduction factor for concrete cracked in shear. The recommended value is $0.6\left[1.0-f_{c k} / 250\right]\left(f_{c k}\right.$ in $\left.\mathrm{MPa}\right) ; f_{c d}$ is design value of concrete compressive strength $\left(=f_{c k} / 1.5\right)$; $f_{c k}$ is characteristic compressive cylinder strength of concrete at 28 days; and $\theta$ is angle between concrete compression strut and wall axis perpendicular to shear force. Here, the values of $\cot \theta$ and $\tan \theta$ are taken as 1.0.

- Diagonal tension failure of the web due to shear:

If $\alpha_{s}=M_{E d} /\left(V_{E d} l_{w}\right) \geq 2.0$, the shear strength is given by $V_{R d, s}$

$$
V_{R d, s}=A_{s w} z f_{y w d} \cot \theta / s
$$

where $V_{R d, s}$ is design value of shear force which can be sustained by the yielding shear reinforcement; $A_{s w}$ is cross-sectional area of shear reinforcement; $f_{y w d}$ is design yield strength of shear reinforcement; $s$ is spacing of stir- rups; $M_{E d}$ is design bending moment at the base of wall; and $V_{E d}$ is design shear force.

If $\alpha_{s}=M_{E d} d\left(V_{E d} l_{w}\right)<2.0$, the shear strength is given by $V_{R d}$

$$
V_{R d}=V_{R d, c}+0.75 \rho_{h} f_{y d, h} b_{w o} a_{s} l_{w}
$$

where $V_{R d}$ is shear resistance of a member with shear reinforcement; $V_{R d, c}$ is design shear resistance of a member without shear reinforcement; $\rho_{h}$ is reinforcement ratio of horizontal web reinforcement; $f_{y d, h}$ is design value of the yield strength of horizontal web reinforcement; and $b_{w o}$ is width of wall web.

\section{LABORATORY EXPERIMENTS}

Seven HSC structural walls were tested under vertical axial loading and in-plane cyclic lateral loading. All specimens were expected to fail in shear either by crushing of the web concrete or yielding of web reinforcement. The parameters investigated include $h_{w} / l_{w}$ of walls, vertical and horizontal web reinforcement ratios $\rho_{v}$ and $\rho_{h}$, and the effect of the boundary elements or the flanges. Specimens J1, J2, $\mathrm{J} 3$, and $\mathrm{J} 4$ had $h_{w} / l_{w}$ of 1.0, whereas Specimens J5, J6, and J7 had $h_{w} / l_{w}$ of 2.0. All specimens were cast with flanges except for Specimen J4, which had no flange. Specimens J1 and J5 were cast with both $\rho_{v}$ and $\rho_{h}$ of $0.28 \%$, which satisfies the minimum requirement of ACI 318 code $^{1}$ and Eurocode $8 .^{2}$ In Specimens J2 and J6, $\rho_{v}$ was increased to $0.75 \%$ while $\rho_{h}$ was kept at $0.28 \%$. In Specimens J3 and J7, $\rho_{h}$ was increased to $0.75 \%$ while $\rho_{v}$ was kept at $0.28 \%$. In Specimen J4, $\rho_{v}$ and $\rho_{h}$ were set to be the same as those in Specimen J1 - that is, $0.28 \%$, to investigate the effect of the flanges. In all the specimens, top and bottom beams were designed to be stiff and strong enough to resist loadings without any significant deformation or damage. Details of specimen dimensions and reinforcements are shown in Fig. 1 and 2. Note that the dimensions and reinforcements for Specimens J5, J6, and J7 were similar to those of Specimens J1, J2, and J3, respectively, except for their wall height, which was $2000 \mathrm{~mm}$ (78.74 in.) instead of $1000 \mathrm{~mm}$ (39.37 in.) and the number of horizontal web reinforcement (11 stirrups instead of six).

\section{Materials}

The concrete mixture design was set to achieve cylinder compressive strength of approximately $100 \mathrm{MPa}(14,500 \mathrm{psi})$. The maximum size of coarse aggregate was $10 \mathrm{~mm}$ (0.39 in.). Silica fume and ground-granulated blast-furnace slag (GGBFS) were used as mineral admixtures. High-range water-reducing admixture was also added to enhance the workability of the concrete because the water-binder ratio $(w / b)$ used was relatively low. The casting of the specimens was done vertically.

The reinforcing bars used were all deformed bars with nominal diameter and yield strength listed in Table 1.

\section{Test setup}

The typical test setup is shown in Fig. 3. Prestressing bars were used to clamp the bottom beam of the specimen to laboratory strong floor to prevent movement or overturning of the specimen. Restraining blocks were also put on both 

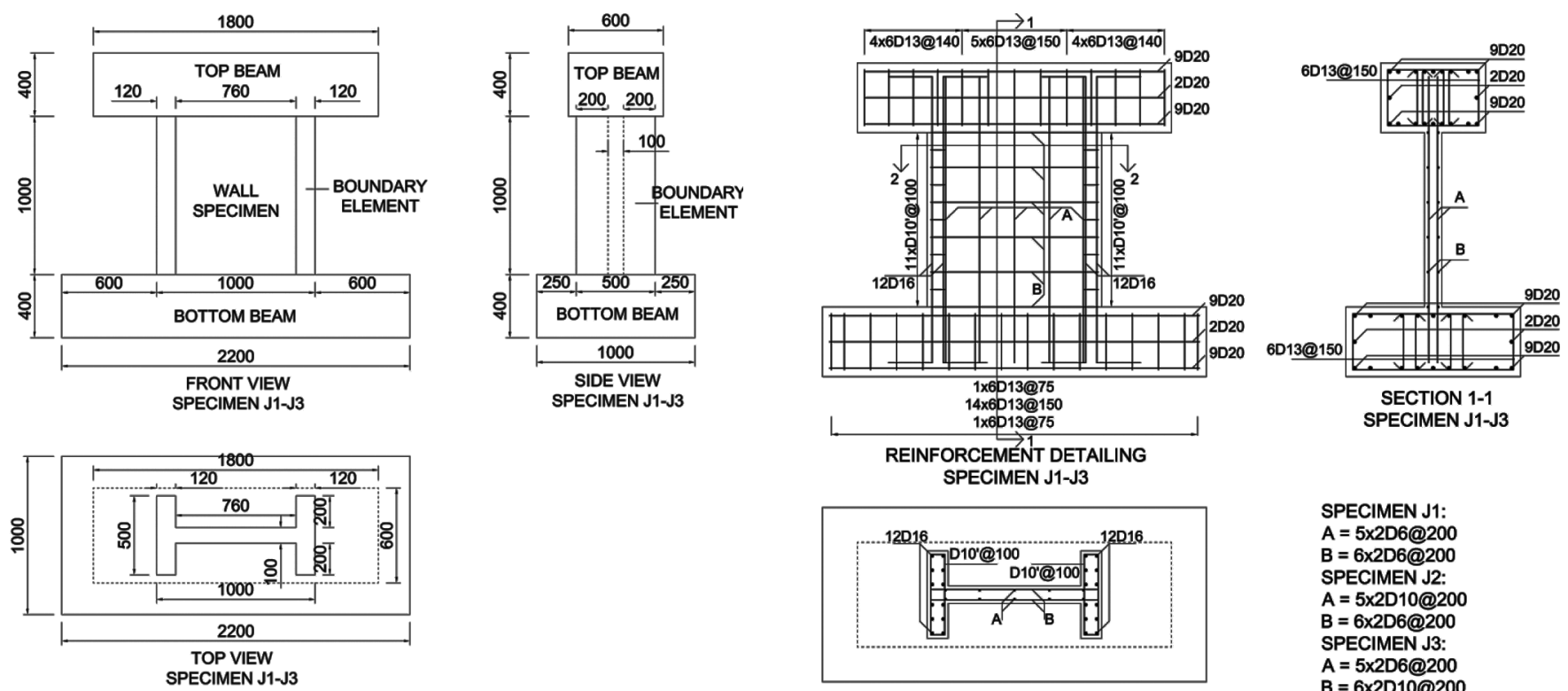

$A=5 \times 2 D 6 @ 200$ $\mathrm{B}=6 \times 2 \mathrm{D} 6200$ SPECIMEN J2: $A=5 \times 2 D 10 @ 200$ B=6x2D6@200 SPECIMEN J3: $\mathrm{A}=5 \times 2 \mathrm{D6} @ 200$ $B=6 \times 2 D 10 @ 200$
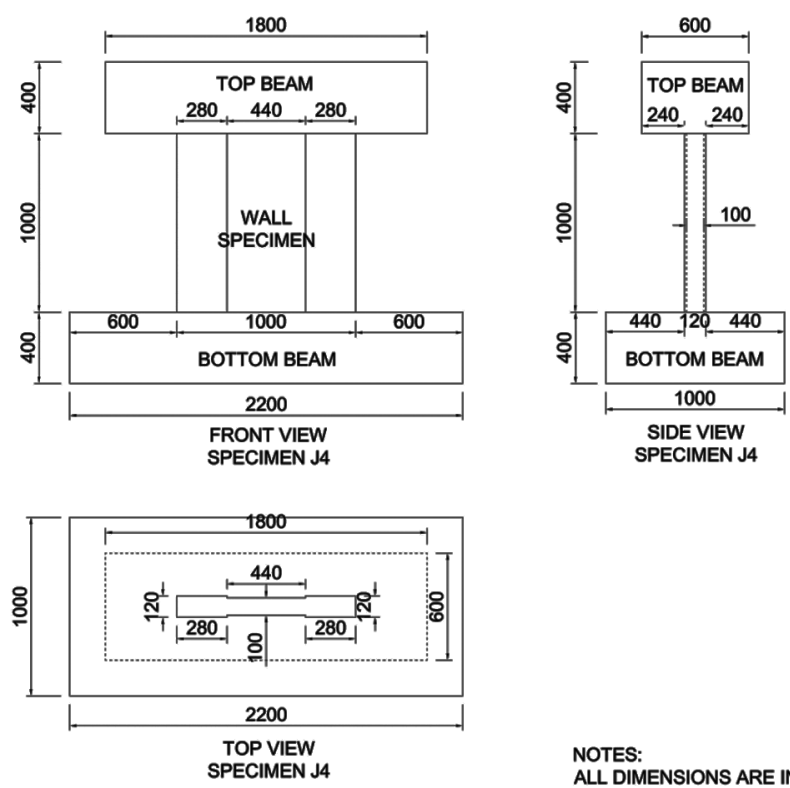

NOTES: $1 \mathrm{MM}=0.04 \mathrm{IN}$

Fig. 1-Specimens J1 through J4 (Specimens J5 through J7 have the same details except that heights of wall web are $2000 \mathrm{~mm}$ [78.74 in.]).

sides of the bottom beam to help prevent movement during testing. The axial load assembly consisted of a vertical loading frame, a $2000 \mathrm{kN}$ (450 kip) hydraulic jack, a $2000 \mathrm{kN}$ (450 kip) load cell, and one set of spreader beam subassembly. The lateral load assembly consisted of the reaction wall, two $1000 \mathrm{kN}$ (225 kip) servo-controlled hydraulic actuators, and one set of loading beam subassembly. Each of the hydraulic actuator was connected to the reaction wall at one end and to the loading beam at the other end. The loading beam was attached to the top beam of the specimen through a hinge which was held in placed by four prestressing rods.

As shown in Fig. 3, the test setup simulated a cantilever RC structural wall that was fixed at the bottom and the loadings were applied at the top of the wall. The static vertical loading from the hydraulic jack was applied to simulate gravity loading

SECTION 2-2

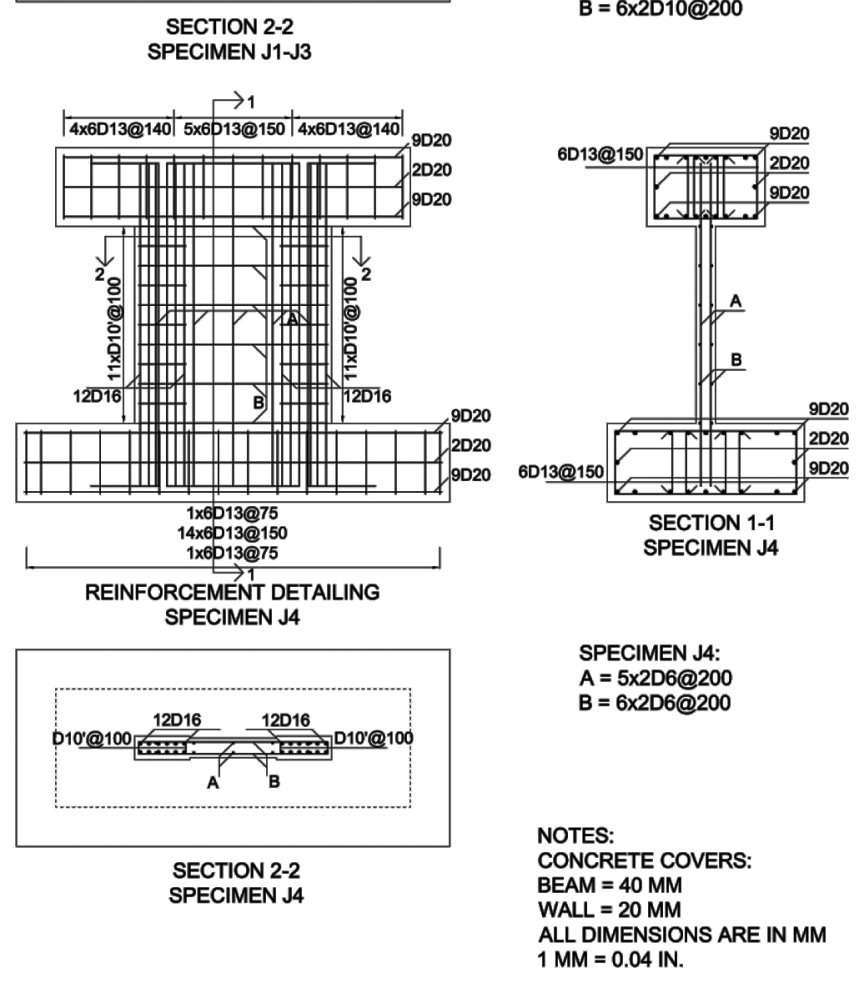

Fig. 2-Reinforcement details for Specimens J1 through J4 (Specimens J5 through J7 have same details except that number of horizontal web reinforcement is 11 pairs). (Note: 5x2D6@200 is five pairs [a total of 10] bars having diameter of $6 \mathrm{~mm}$ [0.236 in.] at $200 \mathrm{~mm}$ [7.87 in.] spacing.)

whereas the cyclic lateral loading from the hydraulic actuators was applied to simulate earthquake loading.

\section{Instrumentation}

Displacements of each wall specimen were measured using linear variable displacement transformers (LVDTs). The in-plane lateral displacement of the top beam was measured at the center of the beam which was the point of resultant force from the hydraulic actuators. This data would be used to plot force-drift curve of the wall specimen. Moreover, the out-of-plane lateral displacement of the top 

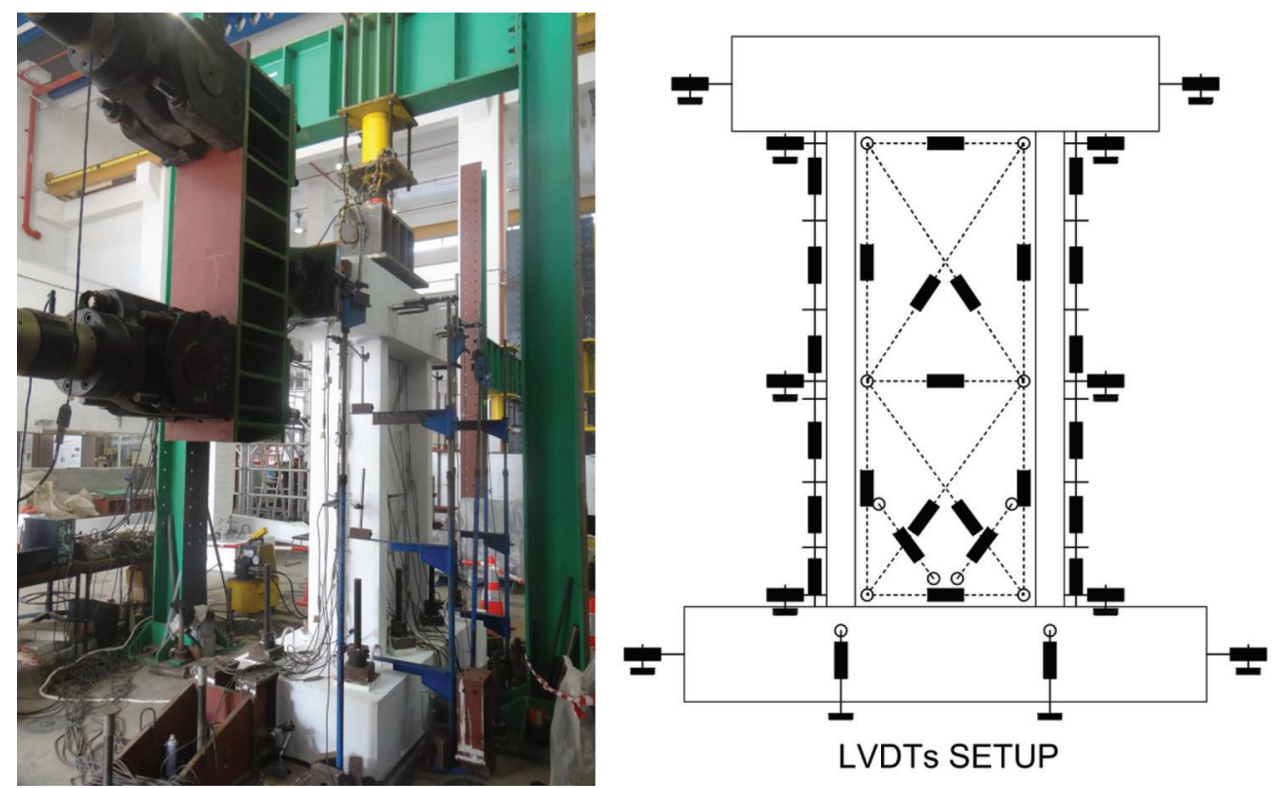

Fig. 3-Overall test setup and LVDT setup.

\section{Table 1-Properties of steel bars}

\begin{tabular}{c|c|c}
\hline $\begin{array}{c}\text { Bar ID } \\
(1)\end{array}$ & $\begin{array}{c}\text { Diameter, mm (in.) } \\
(2)\end{array}$ & $\begin{array}{c}\text { Yield strength, MPa (ksi) } \\
(3)\end{array}$ \\
\hline D6 & $5.94(0.23)$ & $610(88.47)$ \\
\hline D10 & $9.77(0.38)$ & $578(83.83)$ \\
\hline D10' & $9.88(0.39)$ & $617(89.49)$ \\
\hline D13 & $12.82(0.50)$ & $592(85.86)$ \\
\hline D16 & $15.72(0.62)$ & $630(91.37)$ \\
\hline D20 & $19.81(0.78)$ & $591(85.72)$ \\
\hline
\end{tabular}

beam, if any, was also monitored. The bottom beam was monitored against movement and uplift, if any. All LVDTs were attached to independent steel frames that were erected specifically to hold the LVDTs.

Flexural deformations of the wall specimen were measured using a series of LVDTs attached to wall edges along the wall height. The displacements from these LVDTs were then divided by their gauge lengths to obtain the strains at wall edges. From those strains, curvatures along wall height and, thus, the flexural deformations of the wall specimen could be obtained. Shear deformations of the wall web were measured using diagonally placed LVDTs that were attached to the wall web. The shear deformations could be estimated using the changes in diagonal lengths of the wall web. However, flexural deformation components need to be excluded to better estimate shear deformations. Sliding shear deformation was measured using LVDTs that were attached to wall base. Complete LVDT setup is illustrated in Fig. 3.

Strains in the reinforcing bars were measured using strain gauges that were installed on the reinforcing bars at certain locations. For vertical bars, strain gauges were installed at three locations - bottom, middle, and top of the wall. For horizontal bars, strain gauges were also installed at three locations - left end, middle, and right end of wall web.

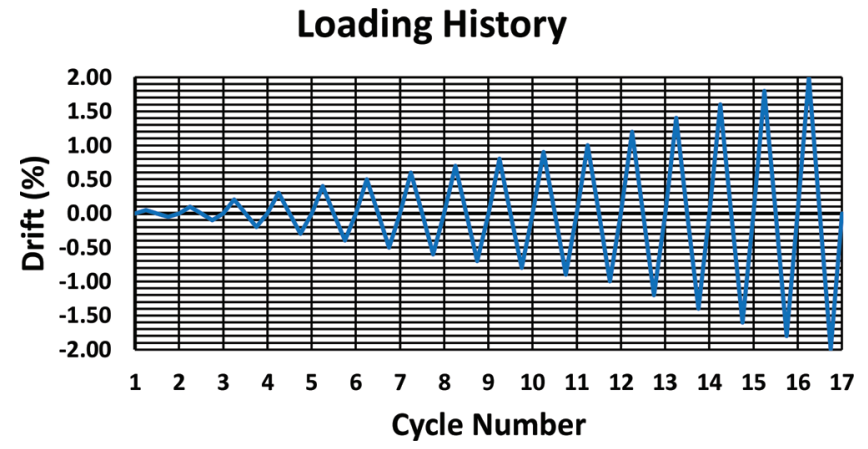

Fig. 4-Loading history.

\section{Test procedure}

First, the axial load was applied gradually using the hydraulic jack until the compressive stress in the wall specimen reached $5 \%$ of the concrete cylinder compressive strength. This ratio was selected to be within the possible range of axial load for RC structural walls in buildings. Structural walls are normally designed to carry an axial load of up to approximately $20 \%$ of their axial capacity or less. At service load, the axial load will be unfactored and during an earthquake, the axial load drops further as the occupants leave the buildings. The ratio of 5\% above considers the capacity of the flanges as well and it is within the acceptable range of axial load during an earthquake. This axial load was maintained constant throughout the test period. The cyclic lateral load was then applied using the hydraulic actuators by displacement control. Each specimen was subjected to the same loading history shown in Fig. 4. In each cycle, there were positive and negative drift amplitudes. The amplitudes were increased gradually in subsequent cycles until the specimen failed abruptly or until the lateral load that could be resisted by the specimen dropped to $70 \%$ of the peak value or lower. In either case, the peak lateral load was considered to be the failure load. At peak amplitudes in each cycle, crack patterns were marked to capture crack propagations. 

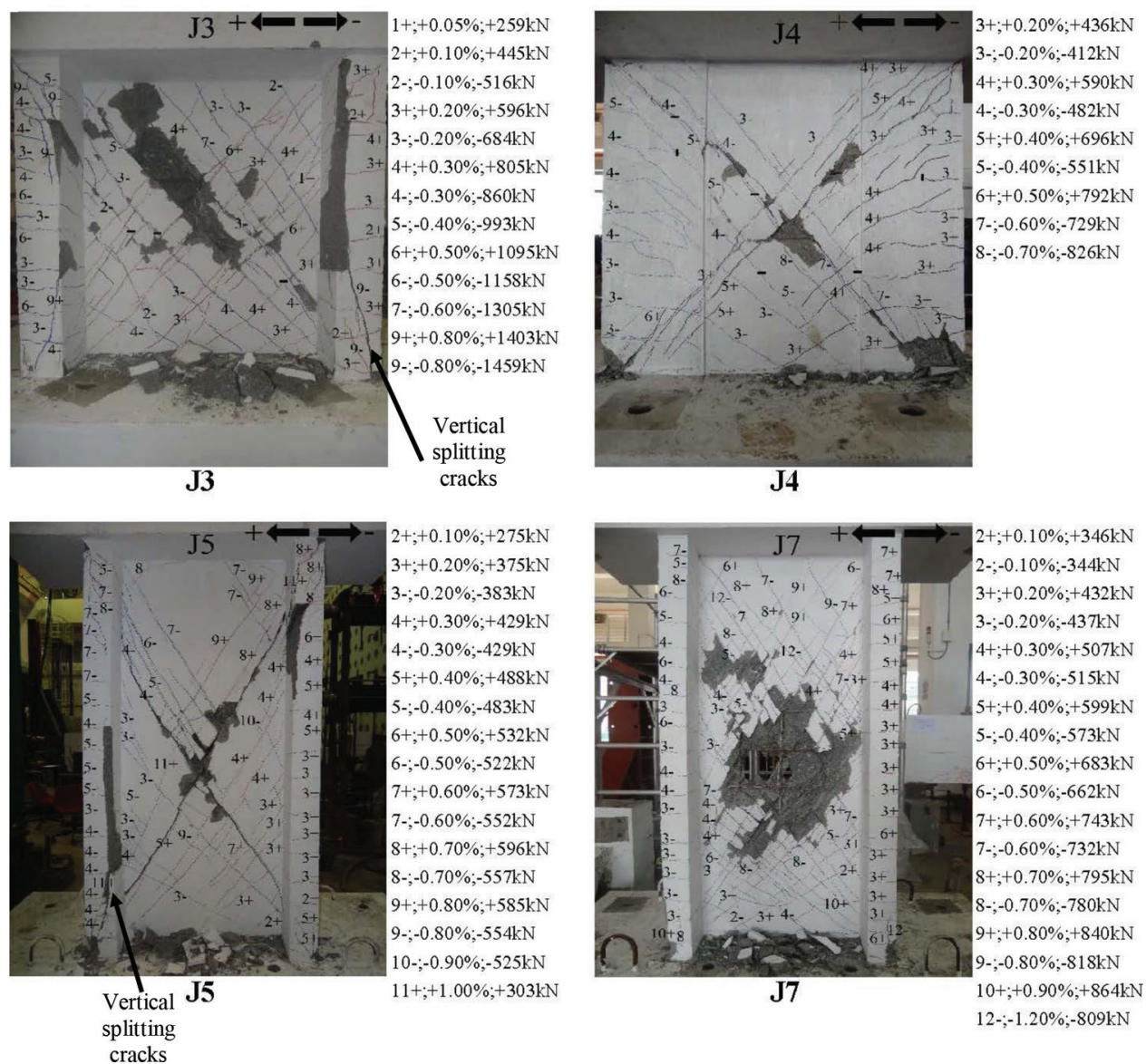

Fig. 5-Crack pattern at end of test of each specimen. Negative direction is from left to right. $2+;+0.10 \% ;+275 \mathrm{kN}$ indicates second cycle in positive direction, drift ratio, and lateral force at respective drift ratio. (Note: $1 \mathrm{kN}=0.22 \mathrm{kip}$.)

Displacements of the specimen and strains in the reinforcing bars were monitored and recorded throughout testing.

\section{EXPERIMENTAL RESULTS AND DISCUSSIONS}

Despite clear individual differences in the wall behavior, the general behavior in terms of crack patterns, drift ratios, lateral deformations, and strains in steel bars for Specimens $\mathrm{J} 1, \mathrm{~J} 2$, and $\mathrm{J} 3$ are qualitatively similar to each other. Hence, their discussions can be represented by Specimen J3. Similarly, the general behavior of Specimens J5 and J6 can be qualitatively represented by Specimen J5. The complete results are described in detail in Chandra and Teng. ${ }^{5}$

\section{Crack patterns and force-drift relationships}

The crack patterns are shown in Fig. 5 with numerical notes on the specimens with an explanation of crack propagations during testing beside each photograph. The first numbers denote cycle numbers while positive or negative signs denote positive or negative direction. The respective drift ratios and lateral forces are given as well. The force-versus-drift ratio curves are shown in Fig. 6, with notes on some significant stages during testing. The recorded maximum forces as well as their respective story drifts are shown as well. These values are also presented for all specimens in Table 2 . For Specimen J1, it was decided that the testing would be continued monotonically in the negative direction starting from the sixth cycle (story drift ratio of $+0.40 \%$ ) onwards until the specimen failed to avoid too much movement at the bottom of the specimen.

Overall, the crack propagations were quite similar in all specimens (Fig. 5), except in Specimens J4 and J7. Normally, diagonal cracks started to occur in the web of each specimen as early as in the second cycle, and the number of cracks increased in the subsequent cycles. In the flanges, horizontal cracks occurred mostly at stirrup locations starting from the third cycle onwards. Failure of the specimen was sudden after the occurrence of vertical splitting cracks in the compression flange as well as crushing of concrete at the bottom of the compression flange (refer to Fig. 5, notes 9for Specimen J3 and 11+ for Specimen J5).

For Specimen J4, at the ninth cycle (last cycle), the drift ratio was supposed to be increased to $+0.80 \%$. However, at a drift ratio of $+0.70 \%$, the applied lateral load for the specimen had already dropped to almost half of its peak value (Fig. 6, Specimen J4). Thus, further positive drift increment was aborted to prevent severe strength degradation, and the testing was continued in the negative direction until failure. Diagonal cracks started to occur at the third cycle together with horizontal cracks at stirrup locations of edge column that was in tension (Fig. 5). Failure of specimen occurred when the concrete at the bottom of edge column was crushed. Furthermore, web crushing was also spotted and horizontal web reinforcement fracture was observed in the middle of wall web where concrete spalled off. 
J3

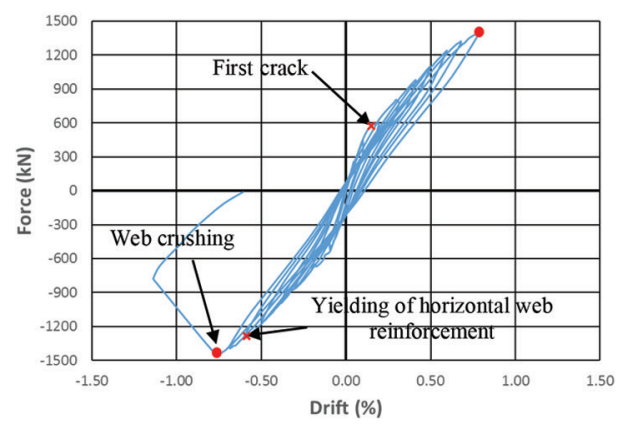

J5

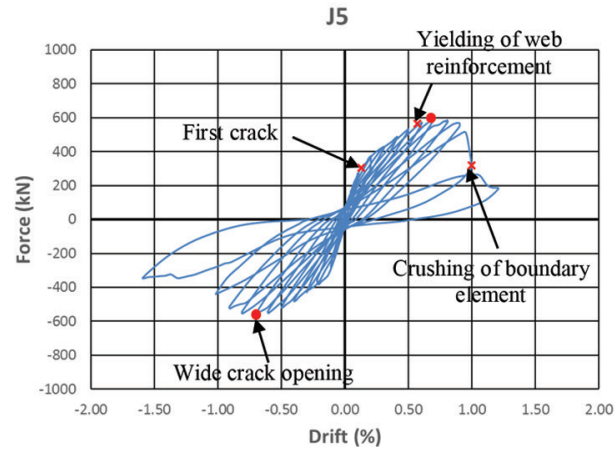

J4

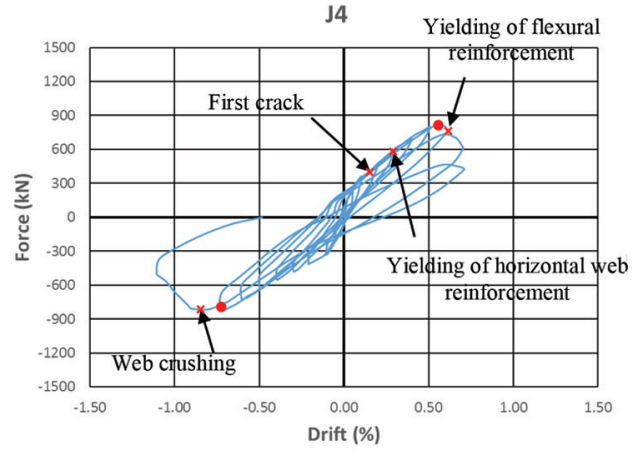

J7 Yielding of horizontal web

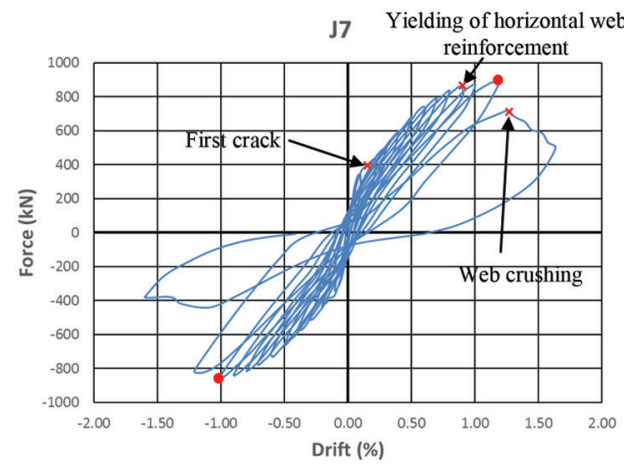

Fig. 6-Force-drift ratio curves of specimens. Dots indicate points of maximum forces recorded and their respective drifts. (Note: $1 \mathrm{kN}=0.22 \mathrm{kip}$.)

When compared to Specimens J1 to J3 and J5 to J6, the crack patterns in Specimen $\mathrm{J} 7$ were quite different. There was no single major diagonal crack as well as no vertical splitting cracks at the flanges in Specimen J7 (Fig. 5). This was likely due to the provision of more horizontal web reinforcement in the web that helped limit the diagonal crack width and hence delay the strength degradation to a later stage of loading or nearer to web crushing stage.

From the force-drift ratio curves (Fig. 6), it can be concluded that all the specimens failed in brittle shear mode. The lateral force dropped significantly after reaching its peak point for specimens with $h_{w} / l_{w}$ of 1.0 (J1 to J4). However, specimens with $h_{w} / l_{w}$ of 2.0 (J5 to J7) are slightly more ductile. Specimen J7 has a drift ratio at peak lateral load of about $1.17 \%$, which can be due to the combination of higher $h_{w} / l_{w}$ and higher horizontal web reinforcement ratio $\rho_{h}$. The average strains in the web reinforcements in all specimens did not reach the yield strain (approximately 0.003 ) at failure. Only in Specimen J4 did some of the flexural reinforcement in the edge column (not in the web) reach yield when the shear failure occurred. The non-yielding of the reinforcement confirmed the brittle shear failure mode of the wall specimens. Thus, the overall behavior of the seven walls tested is governed by shear and they have low deformation capacity.

Note that most of the specimens tested had similar shear strength in the positive and negative directions, meaning that the diagonal cracks that occurred due to loading in one direction did not affect the shear strength in the other direction as long as web crushing had not occurred.

\section{Lateral deformations and strains}

In general, it can be observed in Fig. 7 that as the total wall drift ratio increases, the contribution of the flexural deformation and shear deformation to the total wall drift ratio seems to depend on $h_{w} / l_{w}$ of the walls. For wall specimens with $h_{w} / l_{w}=1.0$ (Specimens J1, J2, and J3), the contribution of shear deformation to the total wall drift was as significant as the contribution of flexural deformation to the total wall drift throughout the full range of lateral loads or drift ratios. For specimens with $h_{w} / l_{w}=2.0$ (Specimens J5, J6, and J7), the flexural deformation was the major contributor to the total wall drift at early stages of loading or before the formation of major diagonal cracks (total drift ratios lower than about $0.70 \%$ ). At higher loads or higher drift ratios nearer failure, shear deformation became significantly more dominant. For Specimen $\mathrm{J} 4\left(h_{w} / l_{w}=1.0\right.$ but no flanges), the results seemed to be inconclusive but they could still be categorized to belong to specimens with $h_{w} / l_{w}=1.0$.

In specimen without flanges (Specimen J4), the sliding shear deformations at higher drift ratios or near failure were significantly larger than those sliding shear deformations in similar specimens $\left(h_{w} / l_{w}=1.0\right)$ but with flanges (Specimens J1, J2, and J3). This indicates that the specimen without flanges is more susceptible to sliding shear failure as compared to those with flanges. Thus, flanges can certainly help to prevent sliding shear failure by providing stiff dowels.

The strain distributions in the vertical and horizontal reinforcements are presented in Fig. 8 and 9. The strains plotted here were obtained from strain gauges located near major diagonal cracks to observe whether the steel bars had yielded during testing. They were also plotted for several drift ratios in either positive or negative loading direction. This was 
Table 2-Specimen properties and experimental results

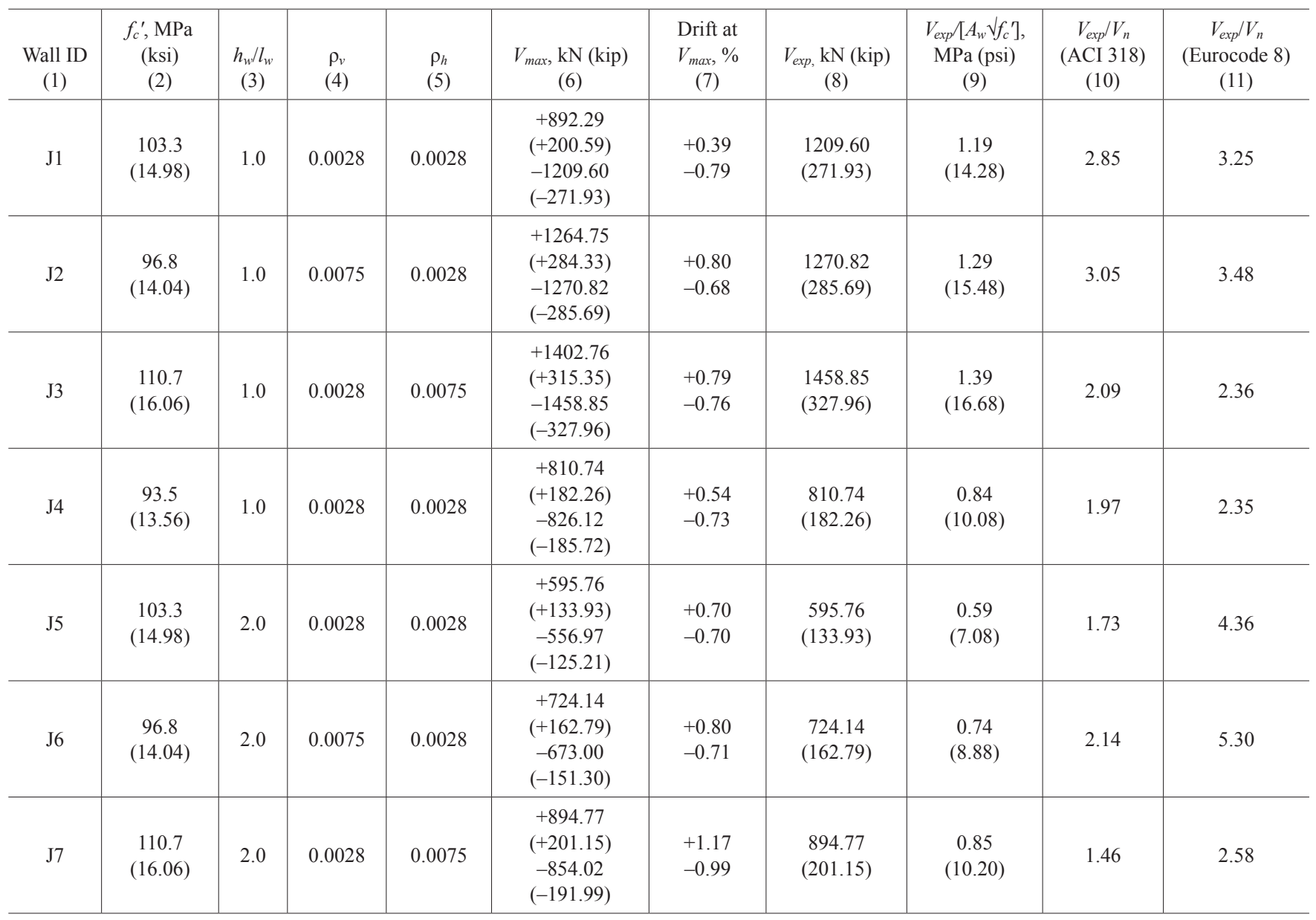

J3

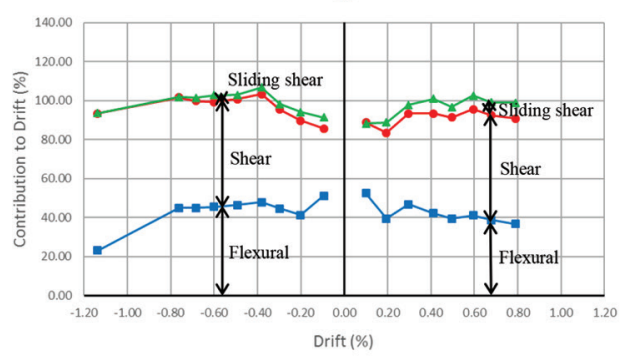

J5

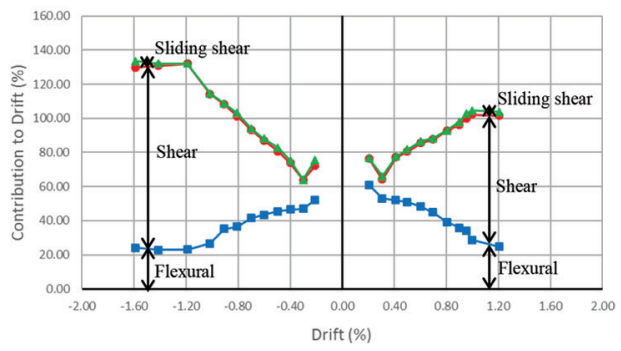

J4

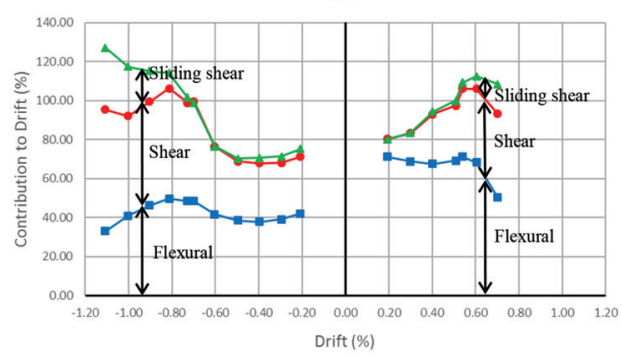

J7

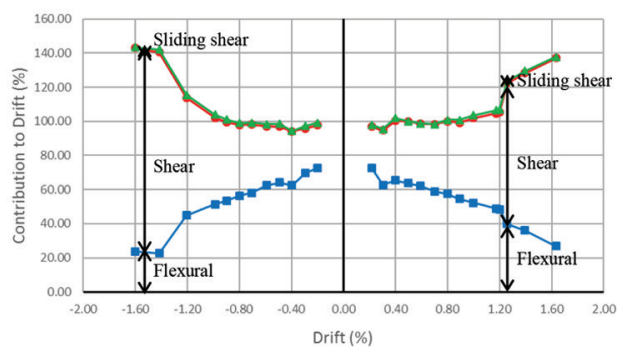

Fig. 7-Contribution of wall deformation components (flexural, shear, and sliding shear) to total drift.

done to observe the strain values in the steel reinforcing bars starting from initial loading until the specimens failed.

At initial loading stage (drift ratio of $0.10 \%$ ), the strains in both vertical bars (Fig. 8) and horizontal bars (Fig. 9) were still low. At this stage, there were only minor cracks in the wall web and major diagonal cracks had not occurred yet. At later stages, the strain values in the steel bars increased with each increment in drift ratio. A sudden increase of strains was normally spotted together with the occurrence of a major diagonal crack at drift ratio of approximately 0.40 to $0.60 \%$. The strains in those steel bars continued to increase until the maximum lateral load was reached.

As can be seen in Fig. 8 and 9, the strain distributions in the steel reinforcing bars across the length and height of the 
J3

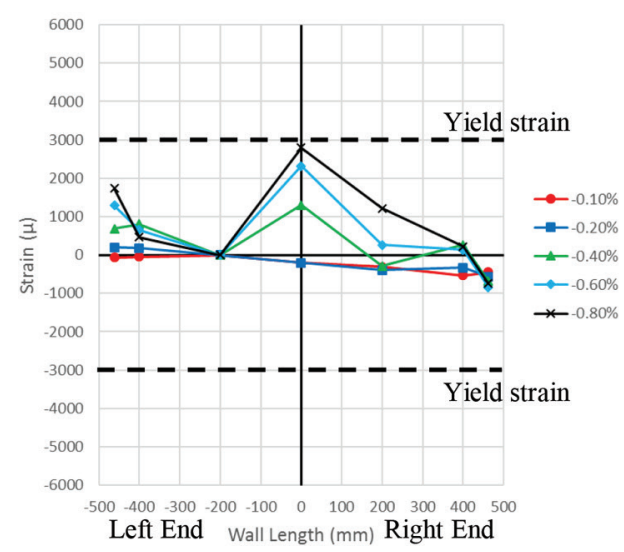

J5

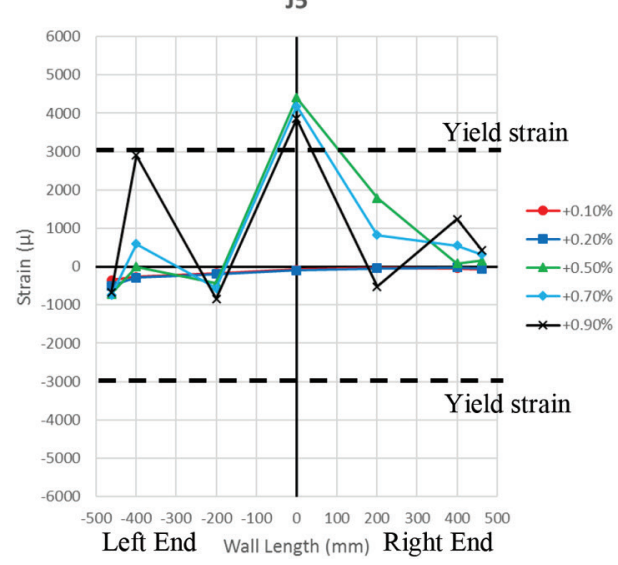

J4

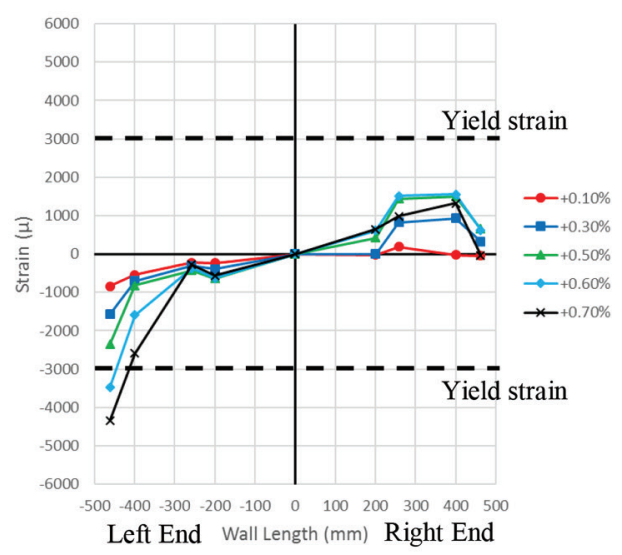

J7

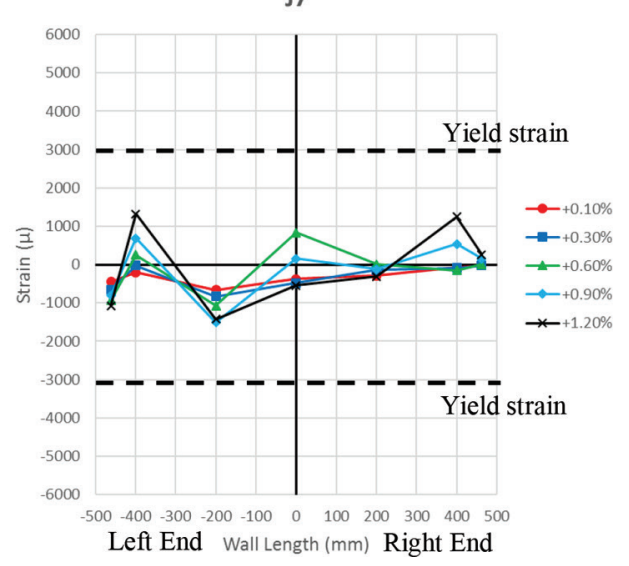

Fig. 8 - Strains in vertical bars near major diagonal cracks at various drift ratios. (Note: $1 \mathrm{~mm}=0.04 \mathrm{in}$.)

walls were irregular and they did not follow the typical flexural behavior. At the peak load, while yielding might occur in some reinforcing bars, more horizontal bars than vertical bars reached the yield strain. The average strains in the horizontal bars were higher than in the vertical bars. Barda et al. ${ }^{6}$ investigated low-rise normal-strength concrete (NSC) walls having $h_{w} / l_{w}$ of $0.25,0.5$, and 1.0 . They concluded that for RC walls having $h_{w} / l_{w}$ of 0.25 and 0.5 , the average strains in vertical bars were higher than those in horizontal bars; while for RC walls having $h_{w} / l_{w}$ of 1.0 , the average strains in the vertical and horizontal bars were approximately equal.

Therefore, based on the authors' experimental results and those from Barda et al., ${ }^{6}$ it can be concluded that in RC walls having $h_{w} / l_{w}$ of less than 1.0 , the vertical web reinforcement is more effective than the horizontal web reinforcement. In $\mathrm{RC}$ walls having $h_{w} / l_{w}$ equal to or greater than 1.0 , the horizontal web reinforcement is more effective than the vertical web reinforcement in resisting lateral forces.

\section{Effect of height-to-length ratio, web reinforcement, and flanges on shear strength}

Specimen properties and experimental results, such as maximum lateral forces $\left(V_{\max }\right)$ and their respective drifts, experimental wall shear strength $\left(V_{\text {exp }}\right)$, and average shear stress are listed in Table 2. $V_{\text {exp }}$ was the maximum lateral force (either positive or negative) before the first shear strength degradation was observed. An average shear stress was calculated by dividing $V_{\text {exp }}$ by the area of wall web $\left(A_{w}\right.$, which is $\left.b_{w} \times l_{w}\right)$. The effects of $h_{w} / l_{w}, \rho_{v}$ and $\rho_{h}$, and the presence of flanges to wall shear strengths are discussed in the following in terms of normalized average shear stress (Table 2, Column 9).

The effect of $h_{w} / l_{w}$ was investigated by comparing similar specimens but differed only in $h_{w} / l_{w}$-that is, Specimen J1 against J5, Specimen J2 against J6, and Specimen J3 against J7. From the data presented in Table 2 and the envelopes of hysteretic curves shown in Fig. 10, it can be seen that those walls having lower $h_{w} / l_{w}$ (1.0 rather than 2.0 in this experiment) exhibit greater shear strength. The normalized average shear stresses (Table 2, Column 9) of walls having $h_{w} / l_{w}$ of 1.0 are between 1.6 and 2.0 times of those of walls having $h_{w} / l_{w}$ of 2.0. Barda et al. ${ }^{6}$ found that increasing $h_{w} / l_{w}$ from 0.5 to 1.0 reduced wall shear strength by $20 \%$. The current authors found that increasing $h_{w} / l_{w}$ from 1.0 to 2.0 reduced wall shear strength by approximately 40 to $50 \%$. Therefore, it can be concluded that, for RC wall having $h_{w} / l_{w}$ ranging from 0.5 to 2.0 , every increment of 0.5 in $h_{w} / l_{w}$ reduces wall shear strength by $20 \%$. This is valid for normal- to very-high-strength concrete walls.

The effect of web reinforcement was investigated by comparing similar specimens that varied only in web reinforcement ratios; that is, Specimen $\mathrm{J} 1$ against $\mathrm{J} 2$ and $\mathrm{J} 3$, and Specimen J5 against J6 and J7. For walls having $h_{w} / l_{w}$ of $1.0(\mathrm{~J} 1, \mathrm{~J} 2$, and $\mathrm{J} 3)$, both vertical and horizontal web reinforcement contributed positively to the shear strength of RC walls. Increasing $\rho_{h}$ and $\rho_{v}$ individually (from $0.28 \%$ to $0.75 \%$ ) resulted in increments of $16.81 \%$ and $8.40 \%$, respec- 

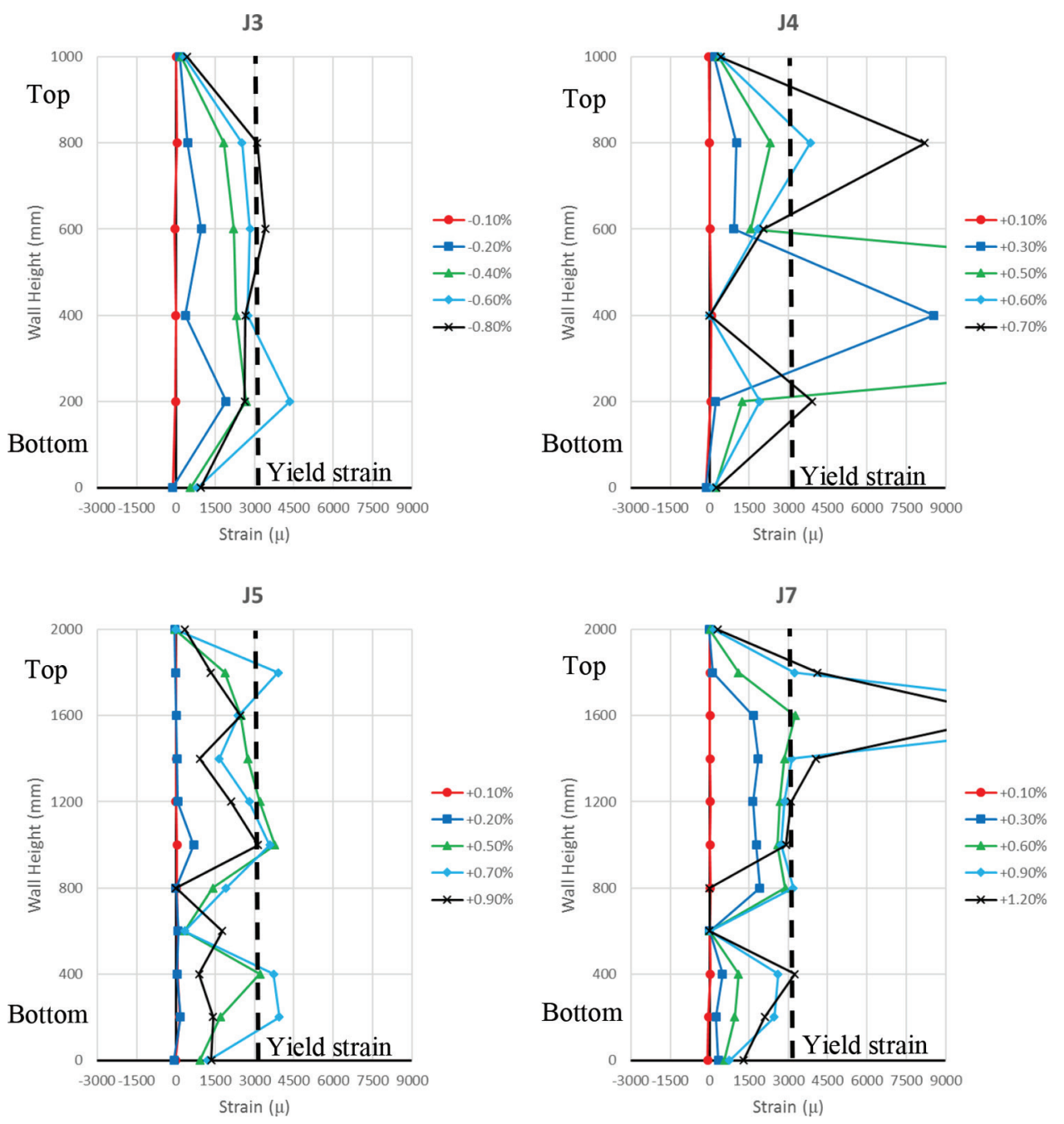

Fig. 9-Strains in horizontal bars near major diagonal cracks at various drift ratios. (Note: $1 \mathrm{~mm}=0.04 \mathrm{in}$.)

tively, in normalized average shear stresses. This means that the horizontal web reinforcement is more effective than the vertical web reinforcement in RC walls having $h_{w} / l_{w}$ of 1.0 .

In walls having $h_{w} / l_{w}$ of 2.0 (J5, J6, and $\mathrm{J} 7$ ), the contributions of the vertical and horizontal web reinforcements to shear strength are even more significant compared to those in walls having $h_{w} / l_{w}$ of 1.0. Increasing $\rho_{v}$ and $\rho_{h}$ individually (from $0.28 \%$ to $0.75 \%$ ) resulted in increments in normalized average shear stresses of $25.42 \%$ and $44.07 \%$, respectively.

From the earlier discussion, it can be concluded that the horizontal web (wall) reinforcement is more effective than the vertical web reinforcement. The effectiveness of horizontal web reinforcement increases from $h_{w} / l_{w}$ of 1.0 up to $h_{w} / l_{w}$ of 2.0. Note, however, that the vertical web reinforcement is also effective in increasing the wall shear strength.

Based on this experiment and experiments from literature, ${ }^{4,6}$ the following conclusion can be made. The vertical web reinforcement is more effective than the horizontal web reinforcement in $\mathrm{RC}$ walls having $h_{w} / l_{w}$ less than 1.0 , while the horizontal web reinforcement is more effective in walls having $h_{w} / l_{w}$ equal to or greater than 1.0. Building codes (ACI $318^{1}$ and Eurocode $8^{2}$ ), however, do not consider the contribution of vertical web reinforcement. They prefer to treat it as an extra safety measure. Indeed, the codes seem to be very conservative for walls having both vertical and horizontal web reinforcements (refer to discussion as follows).

The effect of flanges on shear strength can be seen by comparing Specimens J1 (with flanges) and J4 (without flanges) (refer to Table 2). The presence of large flanges can increase significantly the normalized average shear stress, by $41.67 \%$ in this case. This increment is quite significant because the amount of flexural reinforcement and web reinforcements in both specimens are similar. Obviously, Specimen J1 with larger compression zone area failed at a significantly higher lateral force than Specimen J4. This finding is in agreement with experiment conducted by Corley et al. ${ }^{7}$ on normal-strength concrete walls. The size of the flanges determines how much contribution can be provided by the flanges through the available dowel action.

\section{COMPARISON WITH BUILDING CODES}

In this study, the methods recommended by ACI $318-14^{1}$ and Eurocode $8^{2}$ are used to calculate the shear strengths of $\mathrm{RC}$ walls. Experimental wall shear strengths obtained from this study as well as those from literature ${ }^{4,6-14}$ were used to verify the accuracies of the ACI and Eurocode provisions. A total of 84 specimens failing in shear were selected for comparisons after checking that the specimens satisfied the design requirements of the ACI 318 and Eurocode 8. The 
Envelope Curves

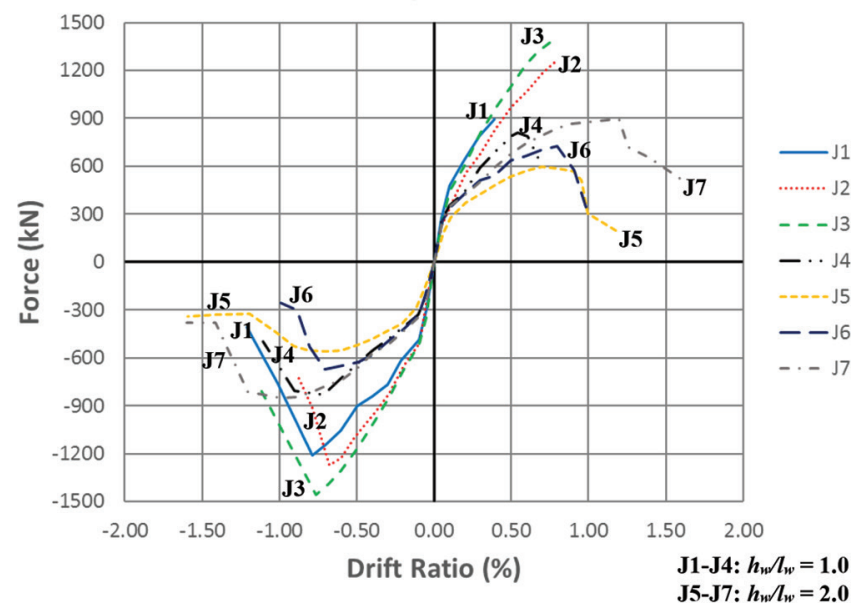

Fig. 10-Envelope curves of specimens. (Note: $1 \mathrm{kN}=0.22 \mathrm{kip}$.)

Table 3-Statistical summary of $V_{\text {exp }} / V_{n}$

\begin{tabular}{c|c|c}
\hline $\begin{array}{c}\text { Statistical parameters } \\
(1)\end{array}$ & $\begin{array}{c}\text { ACI } 318 \\
(2)\end{array}$ & $\begin{array}{c}\text { Eurocode 8 } \\
(3)\end{array}$ \\
\hline Minimum value & 0.67 & 1.21 \\
\hline Maximum value & 3.05 & 5.30 \\
\hline Average value & 1.43 & 2.13 \\
\hline Standard deviation & 0.54 & 0.74 \\
\hline Coefficient of variation & 0.38 & 0.35 \\
\hline
\end{tabular}

Note: Values listed in Table 3 are for a total of 84 walls, including the authors' specimens.

strength of the concrete was not capped. All specimens were provided with web reinforcements, and most of them had flanges. The summary of the comparisons was presented statistically (refer to Table 3 ) in terms of experimental wall shear strength $\left(V_{\text {exp }}\right)$ normalized by nominal wall shear strength $\left(V_{n}\right)$ from ACI 318 and Eurocode 8. The normalized $V_{\text {exp }} / V_{n}$ values were plotted against concrete compressive strength to see the variation of the predictions with respect to concrete compressive strength (Fig. 11).

The predictions of the building code provisions ${ }^{1,2}$ seem to be quite conservative with average values of $V_{\text {exp }} / V_{n}$ of 1.43 for ACI 318 and 2.13 for Eurocode 8. However, their safety factors are not uniform over certain ranges of concrete strengths or $h_{w} / l_{w}$. The Eurocode 8 method leads to the predictions of $V_{\text {exp }} / V_{n}$ with a minimum value of 1.21 , a maximum value of 5.30, and coefficient of variation of 0.35 . The ACI 318 method gives a minimum value of $V_{\text {exp }} / V_{n}$ of 0.67 , a maximum value of 3.05 , and coefficient of variation of 0.38 . Figure 11 shows that the ACI 318 predictions may not be conservative enough for lower strength concrete walls (below $60 \mathrm{MPa}$ [8700 psi]). On the other hand, the Eurocode $8^{2}$ predictions are overly conservative for almost all range of concrete strengths.

The $V_{\text {exp }} / V_{n}$ as calculated using the ACI 318 and Eurocode 8 for HSC walls tested in this study are listed in Table 2. The non-uniform safety factor of the ACI method can be contributed by the fact that it neglects the contribution of
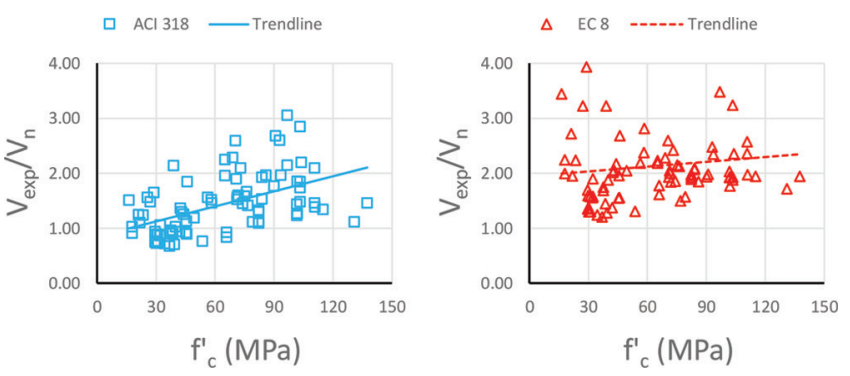

Fig. $11-\mathrm{V}_{\mathrm{exp}} / \mathrm{V}_{\mathrm{n}}$ plotted against concrete compressive strength. (Note: $1 \mathrm{MPa}=145 \mathrm{psi}$.)

vertical wall reinforcement to shear strength. The inaccuracy of the Eurocode 8 appears clearly for walls with higher $h_{w} / l_{w}$. According to Eurocode 8, for walls with moment-toshear ratio (equivalent to $h_{w} / l_{w}$ ) equal to or more than 2.0 , the overall shear strength is determined by the horizontal web reinforcement, while the vertical web reinforcement as well as the so-called concrete contribution are neglected.

The neglect of the contribution of vertical web reinforcement (by both ACI 318 and Eurocode 8) and concrete contribution (by Eurocode 8) should have made the ACI 318 and Eurocode 8 methods very conservative. However, the ratio of the applied moment to axial force and the actual contribution of the vertical and horizontal web reinforcements, as well as the effect of higher concrete strength and $h_{w} / l_{w}$ may play more significant role than expected. Another factor is the dowel action from the boundary element or flanges. It has been found in this study that the presence of large flanges could significantly increase the shear strength of RC walls.

\section{CONCLUSIONS}

Seven HSC walls, having compressive strength of approximately $100 \mathrm{MPa}(14,500 \mathrm{psi})$, were tested under cyclic lateral loading to investigate their shear strength and shear behavior. The parameters included were height-to-length ratio of the walls, vertical and horizontal web reinforcement ratios, and the effects of boundary elements in the form of flanges. Based on the results of this study, the following conclusions can be made:

1. Six of seven specimens tested in this study have similar shear strengths in the positive and negative directions. This means that the diagonal cracks that occurred in one direction of loading did not affect the shear strength in the other direction as long as web crushing had not occurred.

2. For wall specimens with $h_{w} / l_{w}=1.0$, the contribution of shear deformation to the total wall drift was as significant as the contribution of flexural deformation to the total wall drift throughout the full range of lateral loads or drift ratios. For specimens with $h_{w} / l_{w}=2.0$, the flexural deformation was the major contributor to the total wall drift at early stages of loading or before the formation of major diagonal cracks (drift ratios lower than approximately $0.70 \%$ ). At higher loads or higher drift ratios nearer failure, shear deformation became significantly more dominant.

3. Height-to-length ratio has significant effect on the shear strength of RC walls. For RC walls having $h_{w} / l_{w}$ ranging from 0.5 to 2.0 , every increment of 0.5 in $h_{w} / l_{w}$ reduces the shear strength by approximately $20 \%$. 
4. The vertical web reinforcement is more effective than the horizontal web reinforcement in RC walls having $h_{w} / l_{w}$ less than 1.0, while the horizontal web reinforcement is more effective in walls having $h_{w} / l_{w}$ equal to or greater than 1.0.

5. The presence of flanges can significantly increase the shear strength of RC wall failing in web crushing mode due to larger compression area provided by the flanges and through dowel action.

6. ACI 318 predictions may not be conservative enough for lower to normal-strength concrete walls $\left(f_{c}{ }^{\prime}<60 \mathrm{MPa}\right.$ [8700 psi]) while Eurocode 8 predictions are overly conservative for almost all cases. In general, the accuracies of code predictions of shear strength can be enhanced by the inclusions of the contribution of vertical web reinforcement and the dowel action provided by the boundary elements or flanges.

\section{AUTHOR BIOS}

ACI member Susanto Teng is an Associate Professor at Nanyang Technological University, Singapore. He is a member of ACI Committee 435, Deflection of Concrete Building Structures, and Joint ACI-ASCE Committees 421, Design of Reinforced Concrete Slabs, and 445, Shear and Torsion. His research interests include behavior of structural concrete walls, shear strength of slabs, size effect in shear behavior of concrete members, computational modeling of concrete structures, and durability of marine concrete structures.

Jimmy Chandra is a PhD Candidate in the School of Civil and Environmental Engineering, Nanyang Technological University. He is also a Lecturer at Petra Christian University, Surabaya, Indonesia. He received his bachelor of engineering degree from Petra Christian University and his master of engineering degree from Asian Institute of Technology, Khlong Nung, Thailand. His research interests include behavior and seismic performance evaluation of reinforced concrete structures.

\section{ACKNOWLEDGMENTS}

This research is part of the large Competitive Research Program "Underwater Infrastructure and Underwater City of the Future" funded by the National Research Foundation (NRF) of Singapore. The authors are very grateful for the funding. Support by Nanyang Technological University, Singapore, through the School of Civil and Environmental Engineering, is also very much appreciated.

\section{REFERENCES}

1. ACI Committee 318, "Building Code Requirements for Structural Concrete (ACI 318-14) and Commentary (ACI 318R-14)," American Concrete Institute, Farmington Hills, MI, 2014, 519 pp.

2. Comite Europeen de Normalisation, "Eurocode 8: Design of Structures for Earthquake Resistance Part 1: General Rules, Seismic Actions and Rules for Buildings (EN 1998-1)," Comite Europeen de Normalisation (CEN), Brussels, Belgium, 2004, 229 pp.

3. Cardenas, A. E., and Magura, D. D., "Strength of High-Rise Shear Walls-Rectangular Cross Section," Multistory Structures/Lateral Forces, SP-36, American Concrete Institute, Farmington Hills, MI, 1972, pp. 119-150.

4. Cardenas, A. E.; Russell, H. G.; and Corley, W. G., "Strength of Low-Rise Structural Walls," Reinforced Concrete Structures Subjected to Wind and Earthquake Forces, SP-63, American Concrete Institute, Farmington Hills, MI, 1980, pp. 221-242.

5. Chandra, J., and Teng, S., "Shear Behaviour of High Strength Concrete Walls Subjected to Cyclic Lateral Loading," 2015 Interim Research Report to National Research Foundation (NRF), School of Civil and Environmental Engineering, Nanyang Technological University, Singapore, 2015, $329 \mathrm{pp}$.

6. Barda, F.; Hanson, J. M.; and Corley, W. G., "Shear Strength of Low-Rise Walls with Boundary Elements," Reinforced Concrete Structures in Seismic Zones, SP-53, American Concrete Institute, Farmington Hills, MI, 1977, pp. 149-202.

7. Corley, W. G.; Fiorato, A. E.; and Oesterle, R. G., "Structural Walls," Significant Developments in Engineering Practice and Research, SP-72, American Concrete Institute, Farmington Hills, MI, 1981, pp. 77-132.

8. Maeda, Y., "Study on Load-Deflection Characteristics of Reinforced Concrete Shear Walls of High Strength Concrete-Part 1 Lateral Loading Test (in Japanese)," Research Institute Maeda Construction Corporation, Tokyo, Japan, 1986, pp. 97-107.

9. Okamoto, S., "Study on Reactor Building Structure using Ultra-High Strength Materials: Part 1. Bending Shear Test of RC Shear Wall — Outline (in Japanese)," Summaries of Technical Papers of Annual Meeting, Architectural Institute of Japan, Tokyo, Japan, 1990, pp. 1469-1470.

10. Mo, Y. L., and Chan, J., "Behavior of Reinforced Concrete Framed Shear Walls," Nuclear Engineering and Design, V. 166, No. 1, 1996, pp. 55-68. doi: 10.1016/0029-5493(96)01244-7

11. Gupta, A., and Rangan, B. V., "High-Strength Concrete (HSC) Structural Walls," ACI Structural Journal, V. 95, No. 2, Mar.-Apr. 1998, pp. 194-204.

12. Kabeyasawa, T., and Hiraishi, H., "Tests and Analyses of HighStrength Reinforced Concrete Shear Walls in Japan," High-Strength Concrete in Seismic Regions, SP-176, American Concrete Institute, Farmington Hills, MI, 1998, pp. 281-310.

13. Farvashany, F. E.; Foster, S. J.; and Rangan, B. V., "Strength and Deformation of High-Strength Concrete Shear Walls," ACI Structural Journal, V. 105, No. 1, Jan.-Feb. 2008, pp. 21-29.

14. Burgueno, R.; Liu, X.; and Hines, E. M., "Web Crushing Capacity of High-Strength Concrete Structural Walls: Experimental Study," ACI Structural Journal, V. 111, No. 1, Jan.-Feb. 2014, pp. 37-48. 